\title{
Functional abdominal pain: an integrative review study from a biopsychosocial view
}

\author{
Dor abdominal funcional: um estudo de revisão integrativa do ponto de vista biopsicossocial
}

Bianca Aguiar Rodrigues Silva ${ }^{1}$, Patrícia da Graça Leite Speridião², Karina Franco Zihlmann³

DOI 10.5935/2595-0118.20180068

\section{ABSTRACT}

BACKGROUND AND OBJECTIVES: Abdominal pain is one of the most frequent complaints in Pediatric Gastroenterology and may be considered an intricate symptom difficult of immediate differential diagnosis. To perform an integrative review of functional abdominal pain in children.

CONTENTS: It included original and empirical national and international articles, between 2006 and 2016, from the Virtual Health Library, Virtual Health Library - Psychology Brazil (BVS-Psi Brazil) and Pubmed databases, in children aged 6 to 10 years old. The descriptors were: functional abdominal pain, children, gastroenterology. The thematic content was analyzed in the categories: etiology, prevalence, diagnosis process, treatment and intervention strategies and evaluation of coping strategies. Thirty-three articles on functional abdominal pain were found. Factors associated with somatization, anxiety, depression and children's bowel habits were highlighted and should be carefully evaluated by health professionals. Parents may negatively influence the treatment when they adopt encouraging, monitoring, and hypervigilance attitudes.

CONCLUSION: Behavioral, dietary and pharmacological approaches are widely recommended in the treatment of functional abdominal pain. Regarding the emotional behavior, the psychological approach seems to promote good therapeutic results.

Keywords: Abdominal pain, Children, Gastroenterology, Integrative review.

\footnotetext{
1. Universidade Federal de São Paulo, Departamento de Psicologia, Campus Baixada Santista, Santos, SP, Brasil.

2. Universidade Federal de São Paulo, Curso de Nutriçăo, Campus Baixada Santista, Santos, SP, Brasil.

3. Universidade Federal de São Paulo, Curso de Psicologia, Campus Baixada Santista Santos, SP, Brasil.

Submitted on June 15, 2018.

Accepted for publication on September 04, 2018.

Conflict of interests: none - Sponsoring sources: none.

Correspondence to:

Universidade Federal de São Paulo - Campus Baixada Santista

Curso de Psicologia - Psicologia Hospitalar e Psicossomática

Rua Silva Jardim, 136

11015-020 Santos, SP, Brasil.

E-mail: zihlmann@usp.br

(C) Sociedade Brasileira para o Estudo da Dor
}

\section{RESUMO}

JUSTIFICATIVA E OBJETIVOS: A dor abdominal é uma das queixas mais frequentes em Gastroenterologia Pediátrica, podendo ser considerada um sintoma intrincado com dificuldade do diagnóstico diferencial imediato. Realizar revisão integrativa sobre dor abdominal funcional em crianças.

CONTEÚDO: Incluiu artigos originais e empíricos nacionais e internacionais, entre 2006 e 2016, nas bases de dados Biblioteca Virtual de Saúde, Biblioteca Virtual em Saúde - Psicologia Brasil (BVS-Psi Brasil) e Pubmed, em crianças entre 6 e 10 anos. Os descritores foram: dor abdominal funcional, criança, gastroenterologia. A temática foi analisada nas categorias: etiologia, prevalência, processo de diagnóstico, estratégias de tratamento e avaliação das estratégias de enfrentamento. Foram encontrados 33 artigos sobre dor abdominal funcional. Destacou-se fatores associados à somatização, ansiedade, depressão e hábitos evacuatórios das crianças, que devem ser cuidadosamente avaliados pelos profissionais de saúde. Os pais podem influenciar negativamente o tratamento quando adotam atitudes de encorajamento, monitoramento e hipervigilância.

CONCLUSÁO: Abordagens terapêuticas do tipo comportamental, dietética e farmacológica, são amplamente recomendadas no tratamento da dor abdominal funcional. Na vigência de comemorativos do comportamento emocional, a abordagem psicológica parece promover bons resultados terapêuticos.

Descritores: Criança, Dor abdominal, Gastroenterologia, Revisão integrativa.

\section{INTRODUCTION}

Abdominal pain is one of the most frequent complaints in Pediatric Gastroenterology, and it can be considered an intricate symptom with difficulty in the immediate differential diagnosis. Abdominal pain is a common problem in students, and $10 \%$ of this population has recurrent episodes of abdominal pain ${ }^{1}$.

Apley and Naish ${ }^{2}$ conducted one of the first studies about abdominal pain in children, proposing the definition of criteria for the recurrent abdominal pain, such as minimum of three pain episodes in a period of at least three months; and if the pain was severe enough to result in some type of functional loss in the daily activities ${ }^{2}$. Over the years, this definition has become insufficient since other syndromes would also fit into these criteria, such as the irritable bowel syndrome ${ }^{3}$.

The Rome Criteria III ${ }^{4}$ - 2006 consensus - sought to standardize concepts and classifications for the functional gastrointestinal 
disorders (FGIDs), which are characterized by a variable combination of chronic and recurrent gastrointestinal symptoms, not explained by structural, anatomic, metabolic, or biochemical alterations. The warning signals in these criteria are weight loss, dysphagia, fever, frequent vomiting, bleeding, anemia, jaundice, palpable mass, family history of gastrointestinal tract cancer, and change in the pattern of symptoms.

The functional abdominal pain (FAP) or FAP syndrome occurs with the onset of the symptoms at least six months before the diagnosis and presentation of the symptoms in the last three months. The diagnosis criteria for the FAP are: 1 . constant or nearly constant abdominal pain; 2. absence or only occasional relation of pain with physiological events (such as nutrition, defecation, or menstruation); 3. any alteration in the daily functioning; 4. the pain is not concealed; 5 . insufficient symptoms to reach the criteria for another functional gastrointestinal disorder ${ }^{4}$.

Regarding the gastrointestinal conditions specific to childhood, the Rome Criteria $\mathrm{III}^{4}$ established the FAP in children with the following characteristics: 1 . episodic pain or constant abdominal pain. 2. the absence of criteria for other functional gastrointestinal disorders. 3. the absence of evidence of an inflammatory, anatomical, metabolic, or neoplastic process. Besides, in at least $25 \%$ of the time, there should be: 1 . loss of daily functioning; 2 . additional somatic symptoms, such as a headache, pain in the members or difficulty sleeping. The history of the patient associated with the physical exam is recommended for a proper evaluation.

It should be taken into account that some signs, such as peritoneal irritation, are not consistent with the FAP, which implies the need for complementary exams for differential diagnosis, such as blood, type- 1 urine, feces exams, among others, with the purpose of excluding organic causes ${ }^{1}$. Therefore, this study aimed at performing an integrative review of the multifactorial aspects of the FAP, emphasizing the biopsychosocial approach.

\section{CONTENTS}

A survey of the literature was conducted in the databases Biblioteca Virtual em Saúde (BVS, Virtual Health Library), Biblioteca Virtual em Saúde - Psicologia Brasil (BVS- Psi Brasil [Psychology Brazil]), with the terms "functional abdominal pain", "abdominal pain", and "psychological symptoms" in articles published in the Portuguese and English languages between 2006 and 2016. The period was established considering the publication of the Rome Consensus III, in 2006. Only original and empirical articles regarding children from 6 to 12 years old were included. The articles with experts' opinions, editorials, comment sessions, research projects, theses, and dissertations were excluded, as well as literature reviews.

The methodological procedure was based on the integrative review, according to Whittemore e $\mathrm{Knafl}^{5}$. A guiding question was formulated: What is the scientific knowledge (concepts, theories, and practices) available in the national and international literature regarding the functional abdominal pain in children in the 6-10 age group?

Of the 548 articles found based on the descriptors, 448 articles were excluded for presenting a different theme. After reading the abstracts, 57 were excluded for not fitting in the criteria and two for being duplicates. After the complete reading of the articles, nine were excluded for not meeting the criteria. Thus, 33 articles were included in the final sample. Figure 1 shows the flowchart of the articles' selection and exclusion process.

Most of the articles are from abroad, with emphasis on the United States, Netherlands, and Iran. Three Brazilian articles were included. The authorship profile is characterized by professionals from the medical area (pediatricians, gastroenterologists, psychiatrists), besides the psychology and nutrition areas. The predominant journals were from the Pediatrics, Psychology, and Gastroenterology areas. Regarding the study design, the transversal, longitudinal, prospective, and retrospective stood out, but there were also case-control studies, randomized clinical trials, double-blind trials, and placebo-controlled.

Five analytical categories were created from the reading of the articles included in the research. 1. Factors associated with the FAP; 2. FAP prevalence; 3. FAP diagnosis; 4. FAP treatment and intervention strategies; 5; evaluation of the coping strategies and quality of life.

Table 1 shows the articles selected for the execution of the integrative review. The categories created are presented as follows, and the connection of the included articles with the literature about the theme.

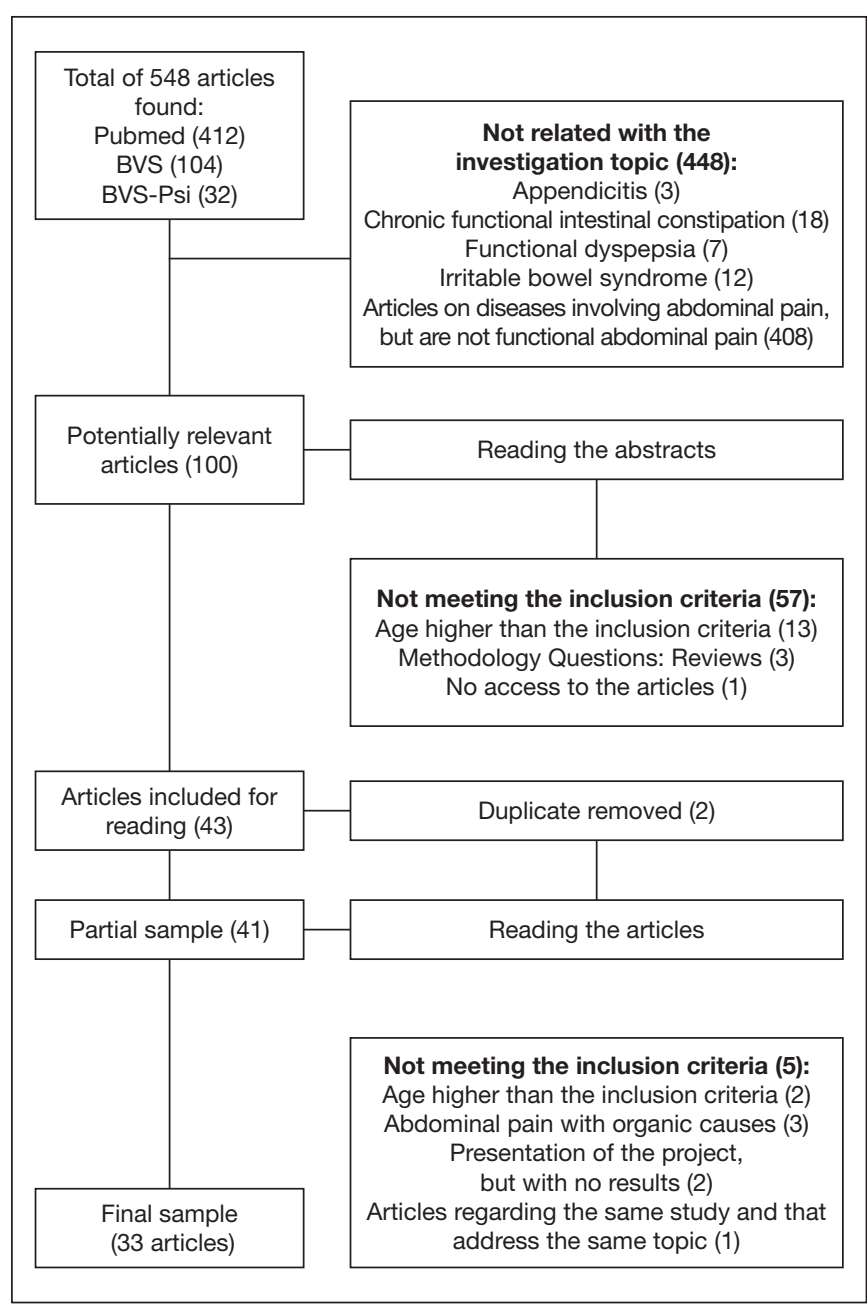

Figure 1. Flowchart of the articles' selection and exclusion process 
Table 1. Articles selected in the final sample and their respective analysis categories

\begin{tabular}{|c|c|c|}
\hline Authors & Methodology & $\begin{array}{l}\text { Analytical } \\
\text { categories* }\end{array}$ \\
\hline 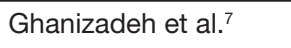 & Transversal & 1 \\
\hline Thornton et al. ${ }^{16}$ & Retrospective longitudinal & 3 \\
\hline Czyzewski et al. ${ }^{8}$ & Prospective longitudinal & 1 \\
\hline Assa et al. ${ }^{36}$ & Case-control & 5 \\
\hline Cunningham et al. ${ }^{6}$ & Transversal & 1 \\
\hline Eftekhari et al. ${ }^{26}$ & $\begin{array}{l}\text { Placebo-controlled clinical } \\
\text { trial }\end{array}$ & 4 \\
\hline Hoekman et al. ${ }^{33}$ & Prospective longitudinal & 4 \\
\hline Ozaki et al. ${ }^{20}$ & Clinical trial & 3 \\
\hline Nieto et al. ${ }^{30}$ & Prospective longitudinal & 4 \\
\hline Saneian et al. ${ }^{27}$ & $\begin{array}{l}\text { Placebo-controlled clinical } \\
\text { trial }\end{array}$ & 4 \\
\hline van Tilburg et al. ${ }^{32}$ & Transversal & 5 \\
\hline Varni et al. ${ }^{37}$ & Case-control & 5 \\
\hline Vivenes et al. ${ }^{14}$ & Prospective longitudinal & 2 \\
\hline Williams et al. ${ }^{9}$ & Transversal & 1 \\
\hline Cunningham et al. ${ }^{40}$ & Transversal & 5 \\
\hline Horst et al. ${ }^{11}$ & Retrospective longitudinal & 1 \\
\hline Levy et al. ${ }^{29}$ & Prospective longitudinal & 4 \\
\hline Zimmerman et al. ${ }^{18}$ & Transversal & 3 \\
\hline $\begin{array}{l}\text { Pourmoghaddas et } \\
\text { al. }{ }^{24}\end{array}$ & $\begin{array}{l}\text { Placebo-controlled clinical } \\
\text { trial }\end{array}$ & 4 \\
\hline Roohafza et al. ${ }^{25}$ & $\begin{array}{l}\text { Placebo-controlled clinical } \\
\text { trial }\end{array}$ & 4 \\
\hline $\begin{array}{l}\text { Rutten, Benninga, } \\
\text { and Vlieger }{ }^{19}\end{array}$ & Transversal & 3 \\
\hline Warschburger et al. ${ }^{35}$ & Transversal & 5 \\
\hline Schurman et al. ${ }^{39}$ & Transversal & 5 \\
\hline Lozinsky et al. ${ }^{12}$ & Clinical trial & 1 \\
\hline Spee et al. ${ }^{15}$ & Transversal & 2,3 \\
\hline van Der Veek et al. ${ }^{31}$ & Prospective longitudinal & 4 \\
\hline van der Veek et al. ${ }^{41}$ & Transversal & 5 \\
\hline $\begin{array}{l}\text { Brands, Purperhart } \\
\text { and Deckers-Kocken }{ }^{28}\end{array}$ & Prospective longitudinal & 4 \\
\hline Helgeland et al. ${ }^{10}$ & Case-control & 1 \\
\hline Sowder et al..$^{13}$ & Prospective longitudinal & 1,4 \\
\hline van Tilburg et al. ${ }^{34}$ & Prospective longitudinal & 4 \\
\hline Dorsa et al. ${ }^{17}$ & Prospective longitudinal & 3 \\
\hline Campo et al. ${ }^{38}$ & $\begin{array}{l}\text { Transversal } \\
\text { Case-control }\end{array}$ & 5 \\
\hline
\end{tabular}

${ }^{*}$ The articles may be included in more than one category since they can approach more than one theme in its scope.

Category 1. Factors associated with functional abdominal pain The main aspects found out include psychiatric disorders, such as anxiety, depression, and the presence of somatization in children with FAP and their parents. Of the children who had abdominal pain for over a year, half has not been diagnosed in a specific FAP subtype. In this study, the children whose parents agreed on the existence of anxiety; presented more pain and incapacitation.
On the other hand, children who reported the existence of anxiety and whose parents disagreed; presented less pain. Another study ${ }^{7}$ observed that more than half of the children with FAP had at least one psychiatric disorder. Despite this association being mentioned by some authors ${ }^{8}$, no difference was found in the level of anxiety between the groups of children with symptoms related to defecation (such as constipation or diarrhea) regarding the symptoms.

Another point was the relation between anxiety and somatization in children with FAP. Williams et. al. ${ }^{9}$ demonstrated that the somatization was more intensely associated with the frequency and intensity of the abdominal pain in children with FAP than the anxiety signs. In turn, Helgeland et al. ${ }^{10}$ pointed out that children with FAP presented somatic symptoms more often, as well as older children whose mothers had symptoms of somatization also presented higher incapacitation. It was also suggested that children might present emotional and somatization problems due to the social learning acquired via the parents. To Horst et al. ${ }^{11}$, somatic intestinal symptoms and depression in children with FAP were relevant for the maintenance of the abdominal pain from childhood into the adult life.

The influence of physiological symptoms and digestive processes was presented by Lozinsky et al. ${ }^{12}$, who found a poor fructose absorption in $30.2 \%$ of the subjects diagnosed with irritable bowel syndrome and FAP. Children in the FAP group presented greater response of the parasympathetic system ${ }^{13}$, which means more difficulty in reaching the homeostasis state than in children in the painless group, as well as the deregulation of the autonomic system against the FAP mechanism.

Thus, most of the articles within this category studied the relationship between FAP and psychiatric disorders without stating a causal relationship, i.e., it is not certain if the psychological disorder developed or was developed after the functional gastrointestinal disorder. But they were unanimous in presenting the influence of these factors in the increase of the pain frequency and intensity in children with functional gastrointestinal disorders. Another risk factor, commented in more than one article, was that older children usually presented more acute symptoms than younger children. One of the hypotheses formulated by the authors is that children with FAP may be hypervigilant to the somatic symptoms $s^{9,11}$.

\section{Category 2. Prevalence of the functional abdominal disease}

Only two articles ${ }^{14,15}$ addressed the epidemiological data after 2006. This information suggests the need for current up-to-date studies on the prevalence of chronic, organic, or functional abdominal pain. Vivenes et al. ${ }^{14}$ observed that among 1,194 children, $11.4 \%$ met the criteria for chronic abdominal pain. In this same case story, the causes of the abdominal pain were organic in $67.1 \%$ of the children, and $32.8 \%$ were functional. Thus, the prevalence of the organic abdominal pain within this population was of $7.71 \%$, while FAP had a $3.77 \%$ prevalence.

The abdominal pain diagnosis of 53 different pediatric gastroenterologists, regarding a population of approximately 16,000 children between 4 and 17 years of age, in a 2-year period, showed an $89.2 \%{ }^{15}$ FAP prevalence in children with abdominal pain. 
Taking into account that the methodology for both studies is distinct, it was difficult to make the comparison. However, in the Vivenes et al. ${ }^{14}$ study, the causes of pain in most of the participants were organic, while in the Spee et al. ${ }^{15}$ study, the causes were functional.

\section{Category 3. Functional abdominal pain diagnosis}

Regarding the consensus employed for the FAP diagnosis, of the six studies included in this category ${ }^{15-20}$, three studies used the Rome III criteria. Regarding the other studies, one was based on the Rome III criteria.

The Rome III reference was used for the diagnostic criteria, highlighting the period of the symptoms so that the patient could meet the FAP criteria. To meet these criteria, at least three consecutive months with the presence of the symptoms are required, starting up to six months of the diagnosis. It is important to point out that in this study, despite the FAP diagnosis being provided by pediatric gastroenterologists, not always the criteria proposed by the Rome $\mathrm{III}^{15}$ were met.

Another important aspect is the fact that the Rome III criteria aimed at reducing the number of tests and the cost of the gastrointestinal diagnosis. However, three studies ${ }^{16-18}$ pointed out the need to exclude the presence of an organic disease. By contrast, the new edition of the Rome $\mathrm{IV}^{21}$ criteria brings an innovative concept in the FAP diagnosis, exempting the physician from the need of excluding organic causes for the abdominal pain to provide the diagnosis of abdominal pain functional disorders ${ }^{22,23}$. Thus, in the abdominal pain functional disorders category, according to the Rome IV criteria, functional dyspepsia, irritable bowel syndrome, abdominal migraine, and unspecified FAP are included ${ }^{22}$.

The three main criteria debated include the minimum consecutive period necessary for the clinical condition to meet the functional diagnosis, analysis of the children's evacuation characteristics, and the need for better specification on the exclusion of organic disease ${ }^{16-18}$. Some authors still mention that the diagnosis of some children is altered with time, after performing invasive exams ${ }^{15}$, such as children who initially received the FAP diagnosis and then were diagnosed with functional constipation ${ }^{17}$.

Dorsa et al. ${ }^{17}$ e Rutten et al. ${ }^{19}$ indicate the need to pay more attention to the characteristics of constipation in children, with the possibility of functional gastrointestinal disorders. In both studies, the authors suggest the hypothesis that these disorders are the same, but with different expressions. Such a hypothesis can be reinforced based on the de Ozaki et al. ${ }^{20}$ study, in which no difference was observed in the results of the water ingestion test by children with the FAP disorders. Only the children with functional dyspepsia had diminished water ingestion capacity when compared to children with FAP or irritable bowel syndrome.

\section{Category 4. Treatment and intervention strategies for the functional abdominal pain}

FAP is a gastrointestinal disorder that does not present a clear etiological mechanism, which makes its diagnosis and treatment a challenge to the practice. The treatments proposed in the selected studies fit into three subcategories: pharmacological, dietary, and behavioral.
No therapeutic action of mebevirin and citalopram ${ }^{24}$ was found in the FAP treatment ${ }^{25}$. Regarding the dietary approach $^{23}$, there were no satisfactory results with probiotics or symbiotics in the FAP treatment ${ }^{24}$. Upon the negative results, the authors suggest two hypotheses for this bad therapeutic answer: 1) short period of usage of the compounds, and 2) the mechanism of action of the disorder would have higher relation with the mental/emotional field. Therefore, the pharmacological or dietary approaches would not have been exclusive to the treatment.

Regarding the behavioral therapeutic, yoga ${ }^{26}$, cognitive behavioral therapy, and social learning ${ }^{27-29}$, besides self-hypnosis ${ }^{30}$, which have shown to be more effective in reducing the pain frequency and intensity in children with FAP. However, the reading of the articles arose a doubt: do the obtained results occurred due to the type of treatment used in each case, or the intensive care received by the patients during the treatment, both on the part of the health team and the family?

Results, also positive, on the biofeedback ${ }^{13}$ treatment, promoted the reduction of pain in $70 \%$ of the children, and the disappearance of the pain in $20 \%$ of the cases.

One single study ${ }^{31}$ discussed the annual costs with the procedures, therapeutic, and drugs, direct non-medical treatment (trips to hospitals, expenses with caregivers and dietetic products), and indirect non-medical treatment (the parents' absences from work, school expenses of children diagnosed with irritable bowel syndrome or FAP. Two hundred and fifty children took part, and the costs were based in the Netherlands economy in 2013. The result found was an annual average of $€ 2,512.31$, with $63.1 \%$ being destined to direct medical costs.

It is worth stressing that of the 12 studies included in this category, only on ${ }^{28}$ presented a qualitative methodological design, with statements from the children and the responsible persons for the attendees, which restricts a lot the performance of the impact analysis of the behavioral therapy in the subjectivity of the participants.

\section{Category 5. Evaluation of the disease's coping strategies and quality of life}

In this category, most of the studies were transversals, and it would be interesting to carry out longitudinal studies to increase the safety on the correlation of the factors involved in the phenomena ${ }^{32}$. Children with functional gastrointestinal disorders such as the FAP may be psychosocial alterations due to the consequences of the symptoms that affect their routines, with the most mentioned being: decrease in the quality of life ${ }^{33}$, absence in the school activities due to pain or medical appointments ${ }^{34}$ and avoidance or isolation from social activities ${ }^{35}$.

The severity of the pain or the disorder symptoms and the use of the catastrophizing as a strategy to cope with the disease were frequent, characterizing them as the most influential factors in the downgrade of the children's quality of life $\mathrm{e}^{36}$.

Since the strategies to cope are usually learned, directly or indirectly, from the parents, most of the studies also analyzed the family relation 37,38 , trying to engage the parents, but most of the times only the mother participated ${ }^{37,38}$. 
As for the coping strategies, it was observed that behavior patterns from the parents, which may be considered positive for the general population, might be negative in this specific situation ${ }^{37-40}$. In this last study, the encouragement and monitoring reaction of the sick child worsened the symptoms of the FAP children. Consequently, the authors suggested the hypothesis that when the parents give too much attention to the disorder, the children become hyper-vigilant and anxious about their symptoms.

In the investigation of the emotional self-perception of children with FAP, the van Der Veek et $\mathrm{al}^{41}$ study reported that children in the abdominal pain group had a slightly lower score in the differentiation of emotions, oral communication of the emotions, and the omission of the emotions than the children without abdominal pain. As for the coping strategies, children with FAP presented more use of distraction than children with some or no pain. Since the differences between the groups were small, it was concluded that children with FAP are not as different regarding the emotional self-perception and use of coping strategies than the general population.

As for the coping strategies used by two groups of children with gastrointestinal disorders ${ }^{32}$, it was learned that children with FAP use more coping strategies than the group of children with the intestinal inflammatory disease and presented a much higher score for depression and incapacitation. In this study ${ }^{32}$, it was observed that children who present catastrophic thoughts and social isolation as coping strategies were linked to higher depression scores, while children who use and seek social support as a strategy had less association with depression and incapacitation.

\section{CONCLUSION}

It was found a relationship between FAP and anxiety, depression, and somatization traits in the studied articles. Regarding the quality of life and coping strategies, it was observed that children with FAP have a decrease in quality of life and tend to be hyper-vigilant about the somatic symptoms, and they may feel them in an intensified way, depending on how this issue is presented by the parents.

Therapeutic approaches were found, such as behavioral, dietary, and pharmacological. The behavioral approach was the one that showed better results in reducing the frequency and intensity of the pain, as well as improvement of the incapacitation.

\section{REFERENCES}

1. Barbosa SMM. Dor abdominal recorrente. In: Consenso sobre Dores Pouco Valorizadas em Crianças. Sáo Paulo: Sociedade Brasileira de Pediatria; 2011.

2. Apley J, Naish N. Recurrent abdominal pains: a field survey of 1,000 school children. Arch Dis Child. 1958;33(168):165-70.

3. Chiou E, Nurko S. Management of functional abdominal pain and irritable bowel syndrome in children and adolescents. Expert Rev Gastroenterol Hepatol. 2010;4(3):293-304

4. Anon J. Apêndice B. Os critérios diagnósticos de Roma III para os distúrbios gastrointestinais funcionais. Arq Gastroenterol. 2012;49(suppl 1):64-8

5. Whittemore R, Knafl K. The integrative review: updated methodology. J Adv Nurs. 2005;52(5):546-53

6. Cunningham NR, Cohen MB, Farrell MK, Mezoff AG, Lynch-Jordan A, Kashikar-Zuck S. Concordant parent-child reports of anxiety predict impairment in youth with functional abdominal pain. J Pediatr Gastroenterol Nutr. 2015;60(3):312-7.

7. Ghanizadeh A, Moaiedy F, Imanieh MH, Askani H, Haghighat M, Dehbozorgi G, et al. Psychiatric disorders and family functioning in children and adolescents with func- tional abdominal pain syndrome. J Gastroenterol Hepatol. 2008;23(7 Pt 1):1132-6.

8. Czyzewski DI, Self MM, Williams AE, Weidler EM, Blatz AM, Shulman RJ. Maintenance of pain in children with functional abdominal pain. J Pediatr Gastroenterol Nutr. 2016;62(3):393-8

9. Williams AE, Czyzewski DI, Self MM, Shulman RJ. Are child anxiety and somatization associated with pain in pain-related functional gastrointestinal disorders? J Health Psychol. 2015;20(4):369-79.

10. Helgeland H, Van Roy B, Sandvik L, Markestad T, Kristensen H. Paediatric functional abdominal pain: significance of child and maternal health. A prospective study. Acta Paediatr. 2011;100(11):1461-7.

11. Horst S, Shelby G, Anderson J, Acra S, Polk DB, Saville BR, et al. Predicting persistence of functional abdominal pain from childhood into young adulthood. Clin Gastroenterol Hepatol. 2014;12(12):2026-32.

12. Lozinsky AC, Boé C, Palmero R, Fagundes-Neto N. Fructose malabsorption in children with functional digestive disorders. Arq Gastroenterol. 2013;50(3):226-30.

13. Sowder E, Gevirtz R, Shapiro W, Ebert C. Restoration of vagal tone: A possible mechanism for functional abdominal pain. Appl. Psychophysiol. Biofeedback. 2010; 35:199-206.

14. Vivenes L, Navarro D, López K, Aguiar C, Polanco I, Belandria K, et al. Dolor abdominal crónico orgánico y funcional en niños: prevalencia en la consulta especializada. Gen. 2015; 69(2):23-7.

15. Spee LA, Lisman-Van Leeuwen Y, Benninga MA, Bierma-Zeinstra SM, Berger MY Prevalence, characteristics, and management of childhood functional abdominal pain in general practice. Scand J Prim Health Care, 2013;31(4):197-202.

16. Thornton GC, Goldacre MJ, Goldacre R, Howarth LJ. Diagnostic outcomes following childhood non-specific abdominal pain: a record-linkage study. Arch Dis Child. 2016;101(4):305-9.

17. Dorsa TK, Hessel G, Neto V, Cardoso M, Pinto, EL. Estudo prospectivo de pacientes pediátricos com dor abdominal crônica. Rev Paul Pediatr. 2007;25(3):247-53.

18. Zimmerman LA, Srinath AI, Goyal A, Bousvaros A, Ducharme P, Szigethy E, et al The overlap of functional abdominal pain in pediatric Crohn's disease. Inflamm Bowe Dis. 2013;19(4):826-31.

19. Rutten JM, Benninga MA, Vlieger AM. IBS and FAPS in children: a comparison of psychological and clinical characteristics. J Pediatr Gastroenterol Nutr. 2014;59(4):493-9.

20. Ozaki RK, Soares AC, Speridiáo Pda G, de Morais MB. Water load test in childhood functional abdominal pain: no relation to food intake and nutritional status. J Pediatr Gastroenterol Nutr. 2015;61(3):330-3.

21. Hyams JS, Di Lorenzo C, Saps, M, Shulman RJ, Staiano A, Tilburg MV. Childhood functional gastrointestinal disorders: child/adolescent. Gastroenterology. 2016;150(6):1456-68

22. Koppen IJ, Nurko S, Saps M, Di Lorenzo C, Benninga MA. The pediatric Rome IV criteria: what's new? Expert Rev Gastroenterol Hepatol. 2017;11(3):193-201.

23. Brusaferro A, Farinelli E, Zenzeri L, Cozzali R, Esposito S. The management of pediatric functional abdominal pain disorders: latest evidence. Paediatr Dugs. 2018;20(3):235-47.

24. Pourmoghaddas Z, Saneian H, Roohafza H, Gholamrezaei A. Mebeverine for pediatric functional abdominal pain: a randomized, placebo-controlled trial. Biomed Res Int. 2014;2014:191026.

25. Roohafza H, Pourmoghaddas Z, Saneian H, Gholamrezaei A. Citalopram for pediatric functional abdominal pain: a randomized, placebo-controlled trial. Neurogastroenterol Motil. 2014;26(11):1642-50.

26. Eftekhari K, Vahedi Z, Kamali Aghdam M, Noemi Diaz D. A randomized double-blind placebo-controlled trial of Lactobacillus reuteri for chronic functional abdominal pain in children. Iran J Pediatr. 2015;25(6):e2612.

27. Saneian H, Pourmoghaddas Z, Roohafza H, Gholamrezaei A. Synbiotic containing Bacillus coagulans and fructo-oligosaccharides for functional abdominal pain in children. Gastroenterol Hepatol From Bed Bench. 2015;8(1):56-65.

28. Brands MM, Purperhart H, Deckers-Kocken JM. A pilot study of yoga treatment in children with functional abdominal pain and irritable bowel syndrome. Complemen Ther Med. 2011;19(3):109-14.

29. Levy RL, Langer SL, Romano JM, Labus J, Walker LS, Murphy TB, et al. Cognitive mediators of treatment outcomes in pediatric functional abdominal pain. Clin J Pain. 2014;30(12):1033-43

30. Nieto R, Hernández E, Boixadós M, Huguet A, Beneitez I, McGrath P. Testing the feasibility of DARWeb: an online intervention for children with functional abdominal pain and their parents. Clin J Pain. 2015;31(6):493-503.

31. van Der Veek SM, Derkx BH, Benninga MA, Boer F, de Haan E. Cognitive behavior therapy for pediatric functional abdominal pain: a randomized controlled trial. Pediatrics. 2013;132(5):e1163-72.

32. van Tilburg MA, Chitkara DK, Palsson OS, Turner M, Blois-Martin N, Ulshen M, et al. Audio-recorded guided imagery treatment reduces functional abdominal pain in children: a pilot study. Pediatrics. 2009;124(5):e890-7.

33. Hoekman DR, Rutten JM, Vlieger AM, Benninga MA, Dijkgraaf MG. Annual costs of care for pediatric irritable bowel syndrome, functional abdominal pain, and functional abdominal pain syndrome. J Pediatr. 2015;167(5):1103-8.e2.

34. van Tilburg MA, Claar RL, Romano JM, Langer SL, Walker LS, Whitehead WE, et al. Role of coping with symptoms in depression and disability: comparison between inflammatory bowel disease and abdominal pain. J Pediatr Gastroenterol Nutr. 2015;61(4):431-6. 
35. Warschburger P, Hänig J, Friedt M, Posovszky C, Schier M, Calvano C. Health-related quality of life in children with abdominal pain due to functional or organic gastrointestinal disorders. J. Pediatr Psychol. 2014;39(1):45-54.

36. Assa A, Ish-Tov A, Rinawi F, Shamir R. School attendance in children with functional abdominal pain and inflammatory bowel diseases. J Pediatr Gastroenterol Nutr. 2015;61(5):553-7.

37. Varni JW, Shulman RJ, Self MM, Nurko S, Saps M, Saeed SA, et al. Symptom profiles in patients with irritable bowel syndrome or functional abdominal pain compared with healthy controls. J Pediatr Gastroenterol Nutr. 2015;61(3):323-9.

38. Campo JV, Bridge J, Lucas A, Savorelli S, Walker L, Di Lorenzo C, et al. Physical and emotional health of mothers of youth with functional abdominal pain. Arch Pediatr
Adolesc Med. 2007;161(2):131-7.

39. Schurman JV, Hunter HL, Danda CE, Friesen CA, Hyman PE, Cocjin JT. Parental illness encouragement behavior among children with functional gastrointestinal disorders: a factor analysis with implications for research and clinical practice. J Clin Psychol Med Settings. 2013;20(2):255-61.

40. Cunningham NR, Lynch-Jordan A, Barnett K, Peugh J, Sil S, Goldschneider K, et al. Child pain catastrophizing mediates the relation between parent responses to pain and disability in youth with functional abdominal pain. J. Pediatr Gastroenterol Nutr. 2014;59(6):732-8.

41. van der Veek SM, Derkx HH, de Haan E, Benninga MA, Boer F. Emotion awareness and coping in children with functional abdominal pain: a controlled study. Soc Sci Med. 2012;74(2):112-9. 